\title{
Microfabricated Passive Magnetic Bead separators
}

\author{
Hansen, Mikkel Fougt; Lund-Olesen, Torsten; Smistrup, Kristian; Bruus, Henrik
}

Published in:

IEEE International Magnetics Conference, 2006. INTERMAG 2006.

Link to article, DOI:

10.1109/INTMAG.2006.375829

Publication date:

2006

Document Version

Publisher's PDF, also known as Version of record

Link back to DTU Orbit

Citation (APA):

Hansen, M. F., Lund-Olesen, T., Smistrup, K., \& Bruus, H. (2006). Microfabricated Passive Magnetic Bead separators. In IEEE International Magnetics Conference, 2006. INTERMAG 2006. IEEE.

https://doi.org/10.1109/INTMAG.2006.375829

\section{General rights}

Copyright and moral rights for the publications made accessible in the public portal are retained by the authors and/or other copyright owners and it is a condition of accessing publications that users recognise and abide by the legal requirements associated with these rights.

- Users may download and print one copy of any publication from the public portal for the purpose of private study or research.

- You may not further distribute the material or use it for any profit-making activity or commercial gain

- You may freely distribute the URL identifying the publication in the public portal

If you believe that this document breaches copyright please contact us providing details, and we will remove access to the work immediately and investigate your claim 
DA-02

\section{Microfabricated Passive Magnetic Bead Separators.}

M. F. Hansen ${ }^{1}$, T. Lund-Olesen ${ }^{1}$, K. Smistrup ${ }^{1}$ and H. Bruus

1. MIC - Department of Micro and Nanotechnology, Technical University of Denmark, Kongens Lyngby, Denmark

The use and manipulation of functionalized magnetic beads for bioanalysis in lab-on-a-chip systems is receiving growing interest [1]. We have developed microfluidic systems with integrated magnetic structures for the capture and release of magnetic beads. The systems are fabricated in silicon by deep reactive ion etching combined with a number of metal deposition and etching steps followed by anodic bonding of a pyrex lid [2,3]. The systems consist of a microfluidic channel integrated with a number of electroplated permalloy elements adjacent to the channel (fig. 1). When these elements are magnetized by an external magnetic field applied perpendicular to the channel, strong magnetic field gradients are created inside the channel, and the beads are captured on the channel walls. When the external field is switched off, the elements demagnetize and the beads are released. Compared to active systems with integrated electromagnetic structures, our systems have the advantage that they are comparatively simpler to fabricate and that on-chip heat generation is avoided. In the talk, we will give an overview of the microfluidic magnetic separation activities at MIC. In this short digest, we present some of the new results obtained on our systems.

We demonstrate magnetic bead capture in a straight microfluidic channel and that the bead capture efficiency is increased by the addition of herringbone mixers. These are ridges at the bottom of the channel which induce transverse fluid convection rolls [4] that bring the beads closer to the elements where the capture forces are large. Figures $1(a)$ and (c) show systems with and without mixer structures. The channel and element dimensions are $1 \times \mathrm{w} \times \mathrm{h}=13500 \times 400 \times 80 \mu \mathrm{m}^{\wedge} 3$ and $4300 \times 150 \times 50 \mu \mathrm{m}^{\wedge} 3$, respectively. The element to channel spacing is $20 \mu \mathrm{m}$. In the mixer systems, the ridges are $30 \mu \mathrm{m}$ tall, $21 \mu \mathrm{m}$ wide and are spaced $60 \mu \mathrm{m}$ apart in groups of five. Figure 1 illustrates the capture of $1 \mu \mathrm{m}$ fluorescence labelled beads (MyOne, Dynal, Norway) from $110 \mu \mathrm{L}$ of a $0.004 \mathrm{w} / \mathrm{v} \%$ bead solution introduced into the systems at a flow rate of $40 \mu \mathrm{L} / \mathrm{min}$. The applied magnetic field of $50 \mathrm{mT}$ was supplied by a table-top electromagnet. The amount of captured beads a each magnetic element was estimated assuming proportionality between the captured volume and the area visible in the fluorescence micrographs in Figs. 1(b) and (d). The points in Fig. 2 show the corresponding normalized estimates of the captured amounts of beads as function of the element number. The bead trajectories were simulated in 3d assuming Stokes' drag. In these simulations, the fluid flow velocity was calculated analytically (without mixer) or numerically (with mixer) and the magnetic field was calculated numerically. The simulated amounts of captured beads vs. element number are shown as the lines in Fig. 2. It is seen that beads are more efficiently captured in systems with integrated mixer structures. The figure also illustrates that simulated bead capture profiles are in good agreement with those found experimentally and hence that simulations are useful for design optimization. In addition to the increased capture efficiency, the mixer structures also facilitate the release of the beads by forcing them from the wall into the central part of the fluid flow. Finally, the mixer functionality can also be utilized in other parts of the lab-on-a-chip system. [1] M.A.M. Gijs, Microfluid Nanofluid 1, 22 (2004).

[2] K. Smistrup, T. Lund-Olesen, M.F. Hansen, P.T. Tang, J. Appl. Phys., in press.

[3] K. Smistrup, B.G. Kjeldsen, J.L. Reimers, M.Dufva, J. Pedersen, M.F. Hansen, Lab Chip 5, 1315 (2005).

[4] A.D. Stroock, S.K.W. Dertinger, A. Ajdari, I. Mezic, H.A. Stone, G.M. Whitesides, Science 295, 650 (2002)

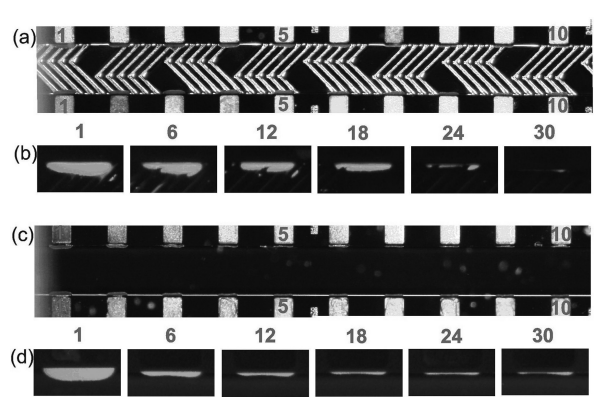

Fig. 1. Micrographs of systems with mixer structures (a) and without mixer structures (c). The channel width is $400 \mu \mathrm{m}$. Fluorescence micrographs of beads captured at the listed element numbers are shown in (b) and (d) for systems with and without mixer structures, respectively. The width of each close-up is $220 \mu \mathrm{m}$.

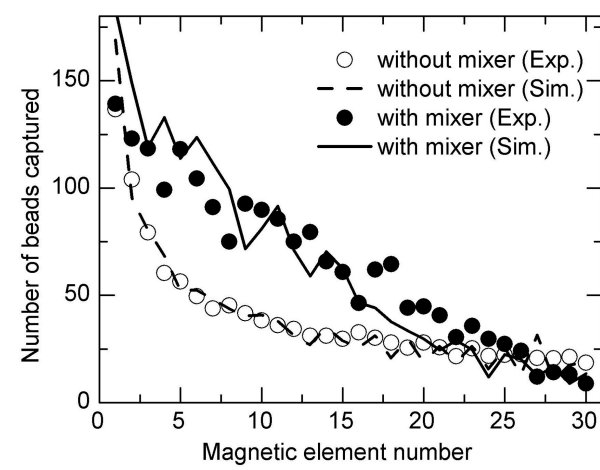

Fig. 2. Amount of captured beads vs. element number for a flow rate of $40 \mu \mathrm{L} / \mathrm{min}$ in systems with and without mixers. Experimental and simulated values are plotted as points and lines, respectively. 